\title{
Chronic meningitis, hydrocephalus and spinal paraplegia in non-systemic histoplasmosis
}

\author{
Meningite crônica, hidrocefalia e paraplegia medular em histoplasmose não-sistêmica
}

Fabiano Reis', Marcondes Cavalcanti França Junior², Anamarli Nucci², Luciano de Souza Queiroz³, Felipe Barjud Pereira do Nascimento', Alberto Rolim Muro Martinez ${ }^{2}$, Marcelo Nunes ${ }^{2}$, Karla de Oliveira Lucca ${ }^{1}$

A 27-year-old immunocompetent agricultural worker presented chronic meningitis and hydrocephalus. Despite CSF and systemic investigation no etiology was defined. Spastic paraplegia installed 15 years later. Spinal and brain MRI are displayed in Figures 1 and 2. The patient developed intracranial hypertension and died days later. A diagnosis of histoplasmosis was made at autopsy (Figure 3).

Histoplamosis as isolated central nervous system disease is rare, being more common in immunosuppressed patients ${ }^{1,2}$. As in this case, it can be a challenging diagnosis, and should be considered in any brain or spinal cord lesion with granulomatous pattern.
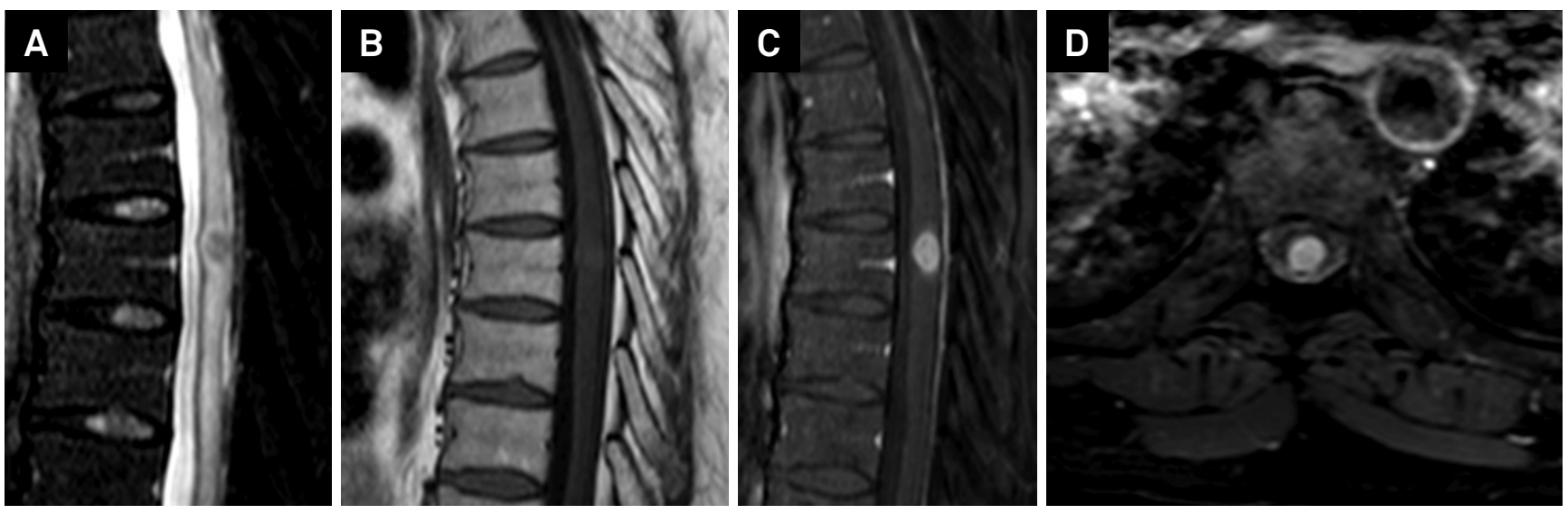

Figure 1. Thoracic spine MRI. A) Sagittal T2 weighted image showing a low signal central lesion in the spinal cord at T7 level, with associated edema above and below. Sagittal T1 weighted images before (B) and after contrast administration (C) and axial after contrast (D) demonstrate its nodular enhancement.

\footnotetext{
Universidade Estadual de Campinas, Faculdade de Ciências Médicas, Departamento de Radiologia, Campinas SP, Brasil;

¿Universidade Estadual de Campinas, Faculdade de Ciências Médicas, Departamento de Neurologia, Campinas SP, Brasil;

${ }^{3}$ Universidade Estadual de Campinas, Faculdade de Ciências Médicas, Departamento de Anatomia Patológia, Campinas SP, Brasil.

Correspondence: Dr. Fabiano Reis; FCM-Unicamp - Departamento de Radiologia; Rua Tessália Vieira de Camargo, 126, Cidade Universitária Zeferino Vaz;

E-mail:fabianoreis2@gmail.com

Conflict of interest: There is no conflict of interest to declare.

Received 02 October 2015; Received in final form 03 March 2016; Accepted 28 March 2016.
} 

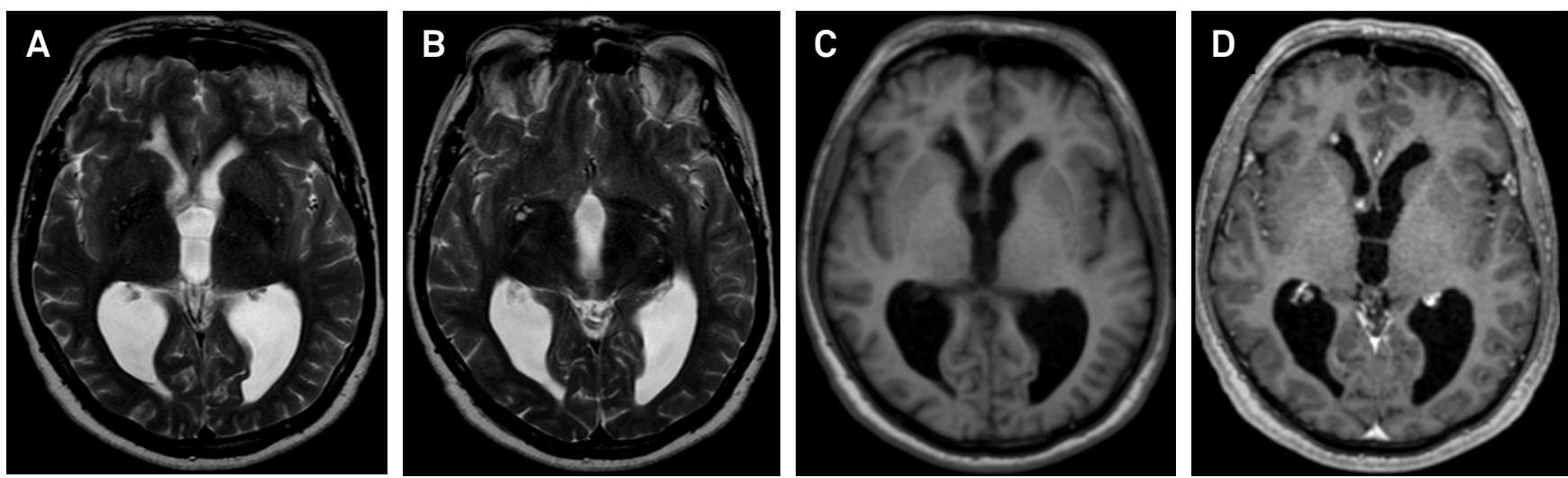

Figure 2. Brain MRI. A and B) axial T2 weighted images demonstrate low signal lesion located at the anterior horn of the right lateral ventricle (arrow) and another isointense lesion located at the right foramen of Monroe, which suggested the possibility of a granulomatous process. Axial T1 weighted images before (C) and after contrast administration (D) demonstrate its nodular enhancement.
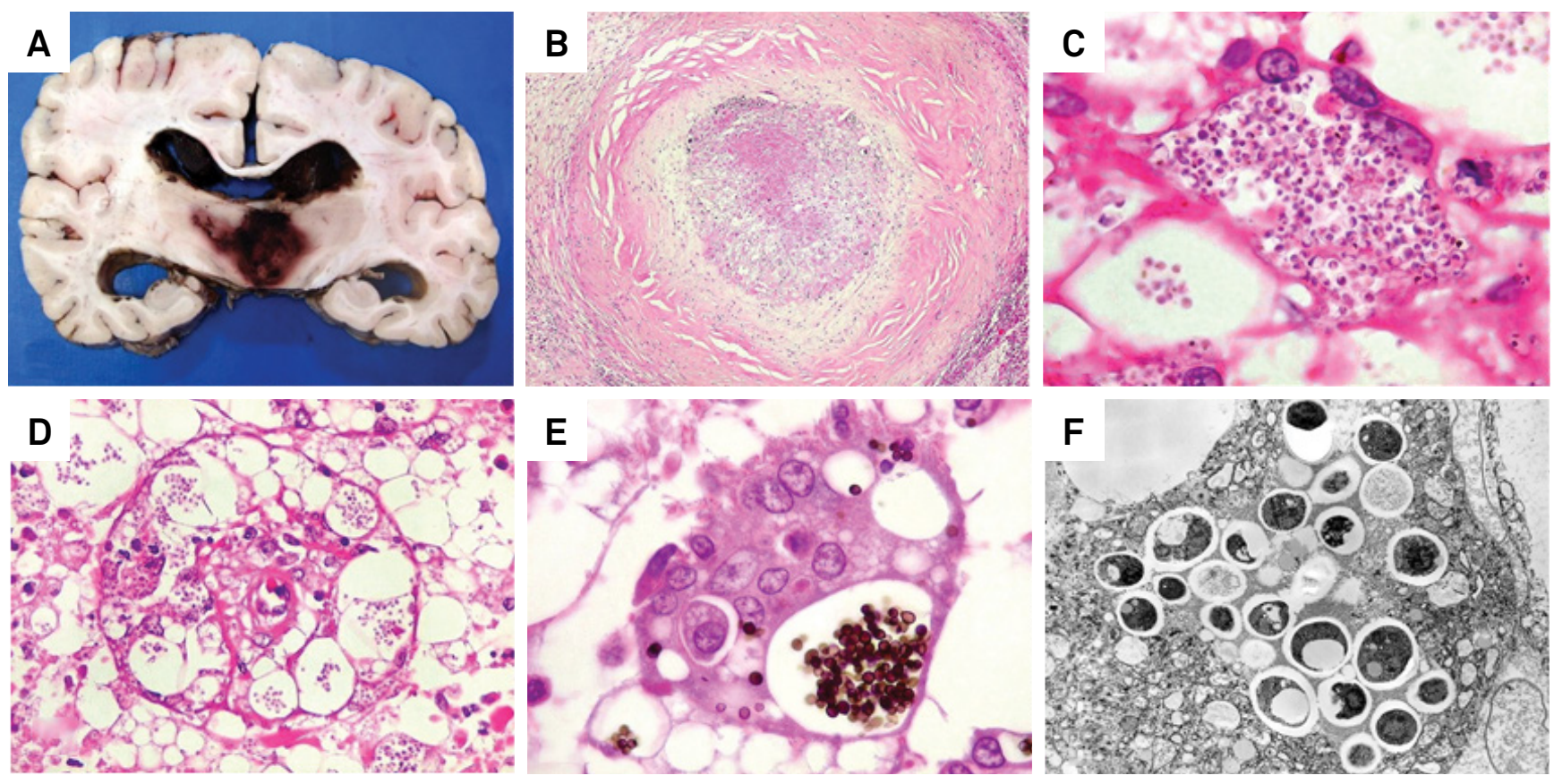

Figure 3. A) Coronal section through brain showing hemorrhagic lesion distending the third ventricle. There is also dilatation of lateral ventricles by blood clots. B) Small subependymal lesion in anterior horn of right lateral ventricle with central caseous necrosis surrounded by thick fibrous capsule and lymphocytic infiltrate. This may have been the entry site for histoplasmas in the brain (primary histoplasmoma). HE, X 40. C) Macrophage in the third ventricle lesion containing abundant microorganisms with features of Histoplasma sp. HE, X 400. D) Small artery in third ventricle wall surrounded and delaminated by parasite filled macrophages. Vasculitis may have caused intraventricular hemorrhage. HE, X 100. E) Histoplasma sp. in macrophage phagosome as small regular yeast forms. Nearly all parasites were intracellular. Grocott's methenamine silver, HE counterstain, X 400. F) Ultrastructure of Histoplasma sp. in a phagocytic cell. Numerous electron dense viable fungi often with a pale vacuole, surrounded by electron lucent capsule. Electron microscopy, X 2500.

1. Kauffman CA. Histoplasmosis: a clinical and laboratory update. Clin Microbiol Rev. 2007;20(1):115-32.

2. Gasparetto EL, Carvalho Neto A, Alberton J, Davaus T,

Pianovski MAD, Yamauchi E et al. Histoplasmoma como lesão isolada do sistema nervoso central em paciente

imunocompetente. Arq Neuropsiquiatr. 2005;63(3A):689-92. doi:10.1590/S0004-282X2005000400027 